\title{
Gun Access and Safety Practices among Older Adults
}

\author{
Hillary D. Lum, ${ }^{1,2}$ Hanna K. Flaten, ${ }^{3}$ and Marian E. Betz ${ }^{3}$ \\ ${ }^{1}$ VA Eastern Colorado GRECC, Denver, CO 80022, USA \\ ${ }^{2}$ Division of Geriatric Medicine, University of Colorado School of Medicine, Aurora, CO 80045, USA \\ ${ }^{3}$ Department of Emergency Medicine, University of Colorado School of Medicine, Aurora, CO 80045, USA
}

Correspondence should be addressed to Hillary D. Lum; hillary.lum@ucdenver.edu

Received 9 October 2015; Accepted 12 January 2016

Academic Editor: Carlos Fernandez-Viadero

Copyright (C) 2016 Hillary D. Lum et al. This is an open access article distributed under the Creative Commons Attribution License, which permits unrestricted use, distribution, and reproduction in any medium, provided the original work is properly cited.

\begin{abstract}
Background. Given high rates of gun ownership among older adults, geriatric providers can assess firearm safety practices using a "5 Ls" approach: Locked; Loaded; Little children; feeling Low; and Learned owner. This study describes gun access and the "5 Ls" among US older adults. Methods. Data on the " 5 Ls" from the Second Injury Control and Risk Survey (ICARIS-2), a national telephone survey conducted by the Centers for Disease Control and Prevention, were analyzed. Weighted variables were used to generate national estimates regarding prevalence of gun ownership and associated gun safety among older adults ( $\geq 55$ years). Results. Of 2939 older adults, 39\% (95\% CI 37\%-42\%) reported $\geq 1$ gun stored at home. Among those with guns at home, 21\% (95\% CI 18-24\%) stored guns loaded and unlocked; 9.2\% (95\% CI 6.6-12\%) had $\geq 1$ child in household; 5.1\% (95\% CI 3.5-6.8\%) reported past-year suicidal ideation and 3.6\% (95\% CI 2.1-5.2\%) reported history of a suicide attempt; and 55\% (95\% CI 51-59\%) stated that $\geq 1$ adult had attended firearm safety workshop. Conclusion. Some older adults may be at elevated risk of firearm injury because of storage practices, suicidal thoughts, or limited safety training. Future work should assess effective approaches to reduce the risk of gun-related injuries among older adults.
\end{abstract}

\section{Introduction}

Gun safety among older adults is relevant to medical and public health professionals, given that older adults experience changes in memory, function, and mood that may increase risks of gun-related injuries and death, including suicide $[1,2]$. Older adults have high rates of gun ownership [3], potentially placing individuals, families, and home healthcare providers at risk [4]; injury risk rises when guns are stored loaded and unlocked [5]. Older adults have high rates of suicide, and gun access is a risk factor for suicide [68]. Healthcare practitioners may play an important role in assessing gun safety and risk of injury in older adults [4, 9-11].

However, currently there are limited data on gun safety among older adults who own guns [12, 13]. Recent work proposed that clinicians ask older adults "Is there a firearm in the home?" and use a " $5 \mathrm{Ls}$ " framework to assess safety: (1) Is it Loaded? (2) Is it Locked? (3) Are Little children present? (4) Is the operator feeling Low? (5) Is the operator Learned? [10]. Using the "5 Ls" framework, this study employs the national Second Injury Control and Risk Survey (ICARIS-2) to examine the prevalence and characteristics of older adult gun owners, as well as gun safety related to firearm storage, suicidal thoughts, presence of children, and firearm safety training.

\section{Methods}

2.1. Survey Design and Participants. The Centers for Disease Control and Prevention conducted the ICARIS-2 survey between July 2001 and February 2003 [14]. The cross-sectional, random-digit-dial telephone survey included English- and Spanish-speaking adults aged $\geq 18$ years in US households. The response rate was $48 \%$ [14]. This analysis includes adults aged $\geq 55(n=29390)$, who accounted for $29 \%$ of all respondents. Adults aged 55 years and older were chosen for this analysis because the survey was conducted approximately 10 years ago. Thus, inclusion of individuals 55 years and older reflects a US population cohort that are adults aged 65 and older at the time of this analysis. Analysis was at the 
level of the individual; survey weighting variables were used to generate national estimates. Weighting was conducted according to the recommended methods as described and recommended for interpretation of survey results [14]. This study was approved by the Colorado Multiple Institutional Review Board.

2.2. Variables. Demographic characteristics included age, gender, self-described race, and Hispanic ethnicity. Household characteristics included living alone, presence of children $(<18$ years), and annual household income. Presence of a firearm was based on the question "Any firearms kept in/around home in the past 12 months?" Participants who did not know $(n=5)$ or declined to answer $(n=64)$ were excluded.

Using the " 5 Ls" framework, analysis addressed firearm storage ("Locked" and "Loaded"); presence of children in the home ("Little children"); suicidal thoughts and prior attempts ("feeling Low"); and prior firearm safety training ("Learned operator"). Survey wording ("Were any firearms ever kept loaded and unlocked while stored in or around your home"?) prevented separation of locked and loaded in terms of storage patterns.

2.3. Statistical Analysis. All responses were summarized using weighted proportions and 95\% Confidence Intervals (CI). Characteristics of respondents with and without firearms at home were compared using Chi Square analyses. Analyses were performed using Stata, version 11.2, with appropriate operations for weighted survey data.

\section{Results}

The survey respondents were $56 \%$ female, and $22 \%$ were at least 75 years old at the time of the survey. In older adults aged $\geq 55$ years, $39 \%$ ( $95 \%$ CI $37 \%-42 \%$ ) reported $\geq 1$ gun stored in or around the home. Figure 1 shows the percentages of individuals with at least 1 firearm in the home by age group. Of individuals with a gun at home, 65\% (95\% CI 62\%-69\%) said $\geq 1$ was a handgun and $69 \%$ (95\% CI 65\%-72\%) reported being the owner of the gun, with a higher proportion of men (92\%, 95\% CI 89-94\%) than women (40\%, 95\% CI 33-46\%) reporting being the owner $(p<0.001)$.

Proportions of respondents reporting a gun at home was higher in the younger cohorts (ages 55-64 and 65-74) and among respondents who were white, had less formal education, and had income above the poverty level (Table 1). Firearm presence at home was lower among individuals living alone. The prevalence of households with a gun varied by region, with the highest levels in the Mountain region (55\%, 95\% CI 46\%-65\%) and lowest in the Mid-Atlantic region (23\%, 95\% CI 18\%-28\%).

Figure 2 shows the prevalence of potential gun safety risks associated with having a gun at home using the " $5 \mathrm{Ls}$ " framework [10]. While the prevalences of children in the household, suicidal ideation, and history of suicide attempt were low, one-fifth $(21 \%$, 95\% CI 18-24\%) of gun owners reported having kept the gun loaded and unlocked at some

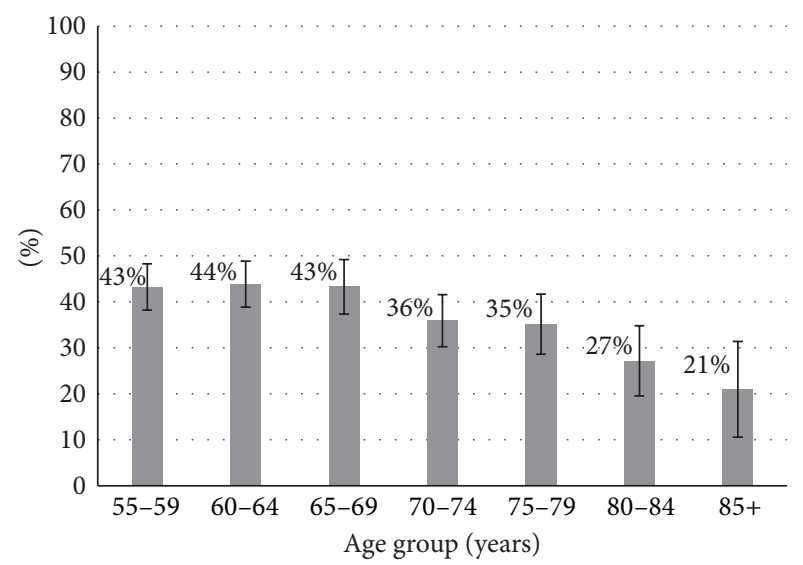

FIgURE 1: Older adults with $\geq 1$ gun at home, by age group $(N=$ 2939). Weighted proportion of older adults with $\geq 1$ firearm in the home, by age group. Error bars represent $95 \%$ Confidence Intervals.

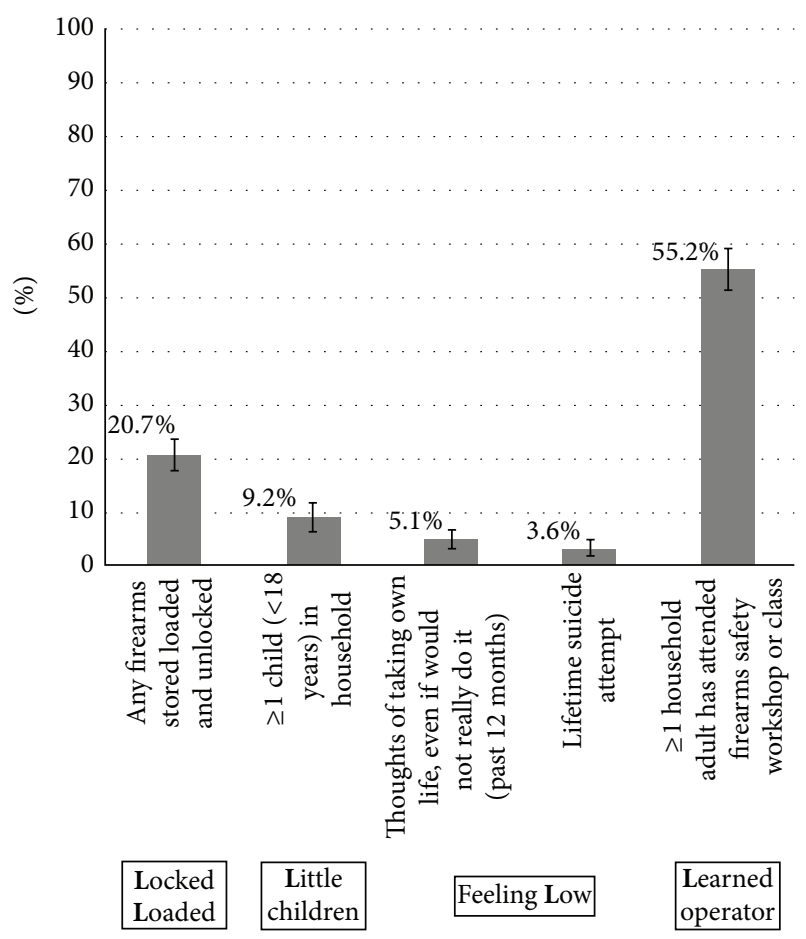

FIGURE 2: Gun safety practices among older adults with $\geq 1$ gun at home. Weighted prevalence of the 5 Ls framework for gun safety among older adult gun owners $(N=987)$. Error bars represent $95 \%$ Confidence Intervals.

point over the past year. Those with a child in the household were more likely to report safe gun storage (i.e., unloaded and locked; 90\%, 95\% CI 82-98\%; versus 77\%, 95\% CI 73$80 \% ; p<0.01)$. Only about half (55\%; 95\% CI 51-59\%) of respondents with a gun at home reported that at least one adult household member had attended a firearm safety workshop or class. There was no association between storing a gun loaded and unlocked and having at least one adult who had attended gun safety training $(p=0.8)$. 
TABLE 1: Characteristics of older adults by presence of $\geq 1$ gun stored in or around the home.

\begin{tabular}{|c|c|c|c|c|c|c|c|c|c|}
\hline \multirow{2}{*}{ Age group $^{* *}$} & \multicolumn{3}{|c|}{ Gun in the home } & \multicolumn{3}{|c|}{ No gun in the home } & \multicolumn{3}{|c|}{ Total } \\
\hline & Weighted $\%^{\mathrm{a}}$ & \multicolumn{2}{|c|}{$95 \% \mathrm{CI}$} & Weighted $\%^{\mathrm{a}}$ & \multicolumn{2}{|c|}{$95 \% \mathrm{CI}$} & Weighted $\%^{\mathrm{a}}$ & \multicolumn{2}{|c|}{$95 \% \mathrm{CI}$} \\
\hline $55-64$ & 47 & 43 & 51 & 39 & 36 & 42 & 42 & 40 & 45 \\
\hline $65-74$ & 36 & 33 & 40 & 36 & 33 & 39 & 36 & 34 & 38 \\
\hline $75-84$ & 15 & 13 & 18 & 21 & 19 & 23 & 19 & 17 & 21 \\
\hline $85+$ & 1.7 & 0.7 & 2.6 & 4.1 & 3.0 & 5.2 & 3.1 & 2.4 & 3.9 \\
\hline Female & 44 & 40 & 48 & 63 & 61 & 66 & 56 & 54 & 58 \\
\hline \multicolumn{10}{|l|}{ Race $^{\mathrm{b}}$} \\
\hline White ${ }^{* *}$ & 89 & 86 & 92 & 79 & 77 & 82 & 83 & 81 & 85 \\
\hline Black $^{* *}$ & 6.0 & 4.1 & 7.9 & 12 & 10 & 14 & 9.6 & 8.2 & 11 \\
\hline Other & 2.7 & 1.5 & 3.9 & 4.5 & 3.1 & 5.9 & 3.8 & 2.8 & 4.8 \\
\hline Live alone $e^{* *}$ & 16 & 14 & 18 & 30 & 28 & 32 & 25 & 23 & 26 \\
\hline Income below poverty level ${ }^{*}$ & 43 & 39 & 47 & 48 & 45 & 52 & 46 & 44 & 49 \\
\hline \multicolumn{10}{|l|}{ Education $^{*}$} \\
\hline College or higher & 34 & 30 & 37 & 36 & 33 & 39 & 35 & 33 & 37 \\
\hline High school & 26 & 23 & 30 & 24 & 21 & 27 & 25 & 23 & 27 \\
\hline Below high school & 40 & 36 & 44 & 40 & 37 & 43 & 40 & 38 & 42 \\
\hline \multicolumn{10}{|l|}{ Census division (with included states) ${ }^{* *}$} \\
\hline New England (CT, MA, ME, NH, RI, VT) & 4.7 & 2.9 & 6.4 & 6.7 & 5.1 & 8.3 & 5.9 & 4.7 & 7.1 \\
\hline Mid-Atlantic (NJ, NY, PA) & 8.9 & 6.8 & 11 & 20 & 18 & 22 & 15 & 14 & 17 \\
\hline East North Central (IL, IN, MI, OH, WI) & 15 & 12 & 17 & 16 & 13 & 18 & 15 & 14 & 17 \\
\hline West North Central (IA, KS, MN, MO, ND, NE, SD) & 7.2 & 5.2 & 9.3 & 6.9 & 5.5 & 8.4 & 7.1 & 5.9 & 8.3 \\
\hline South Atlantic (DC, DE, FL, GA, MD, NC, WV, SC, VA) & 20 & 17 & 23 & 18 & 16 & 21 & 19 & 17 & 21 \\
\hline East South Central (AL, KY, MS, TN) & 8.6 & 6.5 & 11 & 4.6 & 3.4 & 5.8 & 6.2 & 5.1 & 7.3 \\
\hline West South Central (AR, LA, OK, TX) & 13 & 10 & 15 & 8.1 & 6.4 & 9.7 & 9.8 & 8.5 & 11 \\
\hline Mountain (AZ, CO, ID, MT, NM, NV, UT) & 9.6 & 7.1 & 12 & 5.0 & 3.8 & 6.3 & 6.8 & 5.6 & 8.1 \\
\hline Pacific (AK, CA, HI, OR, WA) & 14 & 11 & 16 & 15 & 13 & 17 & 14 & 12.6 & 16.1 \\
\hline
\end{tabular}

$N=2,939$. CI: Confidence Interval. ${ }^{a}$ Survey data includes weighting variables for generation of national estimates. ${ }^{b}$ Multiple responses allowed per participant; ${ }^{*} p \leq 0.05 ;{ }^{* *} p \leq 0.001$ under Pearson chi-square tests; numbers may not add to $100 \%$ due to rounding.

\section{Discussion}

In this national survey of US older adults, nearly $40 \%$ reported a gun in the home, and approximately 1 out of 5 respondents with a gun at home reported that the gun was stored loaded and unlocked. Given the risks for gunrelated injuries among older adults, these findings support the importance of considering firearm safety in older adults. The relevance of healthcare providers asking about gun storage is emphasized by studies demonstrating a high prevalence of loaded firearms in households including individuals with dementia (45\%) [15] or children (50\%) [16]. In this study, less than $10 \%$ with a gun at home reported that a child under age 18 lived in the household and those with children in the home were more likely to report safe gun storage, consistent with other reports [17]. In this era of heightened awareness about firearm-related injuries, healthcare practitioners play an important role in assessing gun safety $[4,18,19]$. Although the ICARIS-2 survey did not ask respondents about cognitive or functional status, future studies, as well as clinical practice, should include detailed assessment of these domains that are also important to the overall safety of older adults and may interact with gun safety practices.
Although the report of suicidal ideation and history of suicide attempt were both low, the importance of assessing risk for self-harm must be emphasized. Rates of firearm suicide rise with age, peaking among those aged 80 to 84 years at an age-adjusted rate of 13.3 per 100,000 [20], and a newly acquired firearm warrants further evaluation due to increased mortality risk $[6,15,21]$. Men account for over $90 \%$ of all suicides among those aged 70 years and older [20]. Given the evidence of "lethal means restriction" (i.e., restricting access to guns and other lethal methods of suicide) as a suicide prevention approach $[22,23]$, healthcare providers should assess firearm access in anyone with suicidal thoughts or behaviors.

There are limitations in interpreting these results. While the overall response rate was only $48 \%$, the weighting variable adjusts for over- or undersampling and nonparticipation and the survey's wide sampling frame further strengthens its generalizability to community-dwelling US adults. Second, the survey relies on self-report of potentially sensitive topics (firearms and suicidal thoughts) without external verification for accuracy. Social desirability may have biased responses to sensitive questions, although this would likely be in a direction that would overestimate gun safety. Temporal 
changes in gun ownership are also a potential limitation, as current gun safety practices may have changed since the survey was conducted. Still, these data are the most recent national estimates with information about the " $5 \mathrm{Ls}$ " framework at the individual level.

\section{Conclusions}

This study provides information about firearm safety practices among US older adults. It emphasizes the potentially elevated risk of firearm injury because of storage practices, suicidal thoughts, or limited firearm safety training. Geriatric practitioners and other health care providers can use the " $5 \mathrm{Ls}$ " framework to identify older adults potentially at risk for firearm injury, including those storing guns loaded and unlocked, those with suicidal ideation, and those with limited formal gun safety training. These findings support the need for research to identify effective approaches to assess gun safety and reduce the risk of gun-related injuries among older adults and their household members.

\section{Disclosure}

No sponsor had any direct involvement in study design, methods, subject recruitment, data collection, analysis, or paper preparation. This work was presented as a poster, and abstract was published in annual meeting issue: "Hillary D. Lum, Hanna K. Flaten, Marian E. Betz. Firearm Access and Safety Practices Among Older Adults in the US. (2015), Society for Academic Emergency Medicine Annual Meeting Abstracts. Academic Emergency Medicine, 22: S41. doi: 10.1111/acem.12644."

\section{Disclaimer}

The views in this paper are those of the authors and do not represent the views of the Department of Veterans Affairs or of the funding agencies.

\section{Conflict of Interests}

The authors have no conflict of interests.

\section{Acknowledgments}

The authors thank Drs. Matthew Miller and Carol Runyan for their thoughtful comments on this study and paper. Special thanks are due to Joanna Dukes for assistance with paper preparation. This work was supported by the Paul B. Beeson Career Development Award Program (The National Institute on Aging, AFAR, The John A. Hartford Foundation, and The Atlantic Philanthropies; K23AG043123-Betz).

\section{References}

[1] B. Mertens and S. B. Sorenson, "Current considerations about the elderly and firearms," American Journal of Public Health, vol. 102, no. 3, pp. 396-400, 2012.
[2] A. L. Kellermann, F. P. Rivara, G. Somes et al., "Suicide in the home in relation to gun ownership," The New England Journal of Medicine, vol. 327, no. 7, pp. 467-472, 1992.

[3] L. Hepburn, M. Miller, D. Azrael, and D. Hemenway, "The US gun stock: results from the 2004 national firearms survey," Injury Prevention, vol. 13, no. 1, pp. 15-19, 2007.

[4] R. Butkus, R. Doherty, and H. Daniel, "Reducing firearmrelated injuries and deaths in the United States: executive summary of a policy position paper from the American College of Physicians," Annals of Internal Medicine, vol. 160, no. 12, pp. 858-860, 2014.

[5] M. Miller, D. Azrael, D. Hemenway, and M. Vriniotis, "Firearm storage practices and rates of unintentional firearm deaths in the United States," Accident Analysis and Prevention, vol. 37, no. 4, pp. 661-667, 2005.

[6] C. W. Barber and M. J. Miller, "Reducing a suicidal person's access to lethal means of suicide: a research agenda," American Journal of Preventive Medicine, vol. 47, no. 3, supplement 2, pp. S264-S274, 2014.

[7] M. Miller, C. Barber, R. A. White, and D. Azrael, "Firearms and suicide in the United States: is risk independent of underlying suicidal behavior?" American Journal of Epidemiology, vol. 178, no. 6, pp. 946-955, 2013.

[8] M. Miller, S. J. Lippmann, D. Azrael, and D. Hemenway, "Household firearm ownership and rates of suicide across the 50 United States," Journal of Trauma-Injury, Infection and Critical Care, vol. 62, no. 4, pp. 1029-1034, 2007.

[9] M. Narayan, "Guns and nurses", American Journal of Nursing, vol. 114, no. 1, p. 11, 2014.

[10] E. M. Pinholt, J. D. Mitchell, J. H. Butler, and H. Kumar, “Is there a gun in the home?' assessing the risks of gun ownership in older adults," Journal of the American Geriatrics Society, vol. 62, no. 6, pp. 1142-1146, 2014.

[11] S. Frattaroli, D. W. Webster, and G. J. Wintemute, "Implementing a public health approach to gun violence prevention: the importance of physician engagement," Annals of Internal Medicine, vol. 158, no. 9, pp. 697-698, 2013.

[12] M. B. Kapp, "Geriatric patients, firearms, and physicians," Annals of Internal Medicine, vol. 159, no. 6, pp. 421-422, 2013.

[13] R. M. Johnson, T. Coyne-Beasley, and C. W. Runyan, "Firearm ownership and storage practices, U.S. households, 1992-2002. A systematic review," American Journal of Preventive Medicine, vol. 27, no. 2, pp. 173-182, 2004.

[14] United States Department of Health and Human Services. Centers for Disease Control and Prevention, "Second injury control and risk survey (ICARIS-2)," OMB Number 2001996-00599, United States Department of Health and Human Services, CDC, Atlanta, Ga, USA, 2001, http://www.cdc.gov/ Injury/wisqars/pdf/ICARIS2-PublicUse-DataSet-Documentation.pdf.

[15] K. B. Spangenberg, M. T. Wagner, S. Hendrix, and D. L. Bachman, "Firearm presence in households of patients with Alzheimer's disease and related dementias," Journal of the American Geriatrics Society, vol. 47, no. 10, pp. 1183-1186, 1999.

[16] R. H. DuRant, S. Barkin, J. A. Craig, V. A. Weiley, E. H. Ip, and R. C. Wasserman, "Firearm ownership and storage patterns among families with children who receive well-child care in pediatric offices," Pediatrics, vol. 119, no. 6, pp. el271-e1279, 2007, Erratum in: Pediatrics, vol. 120, no. 2, p. 460, 2007.

[17] T. Coyne-Beasley, C. W. Runyan, L. Baccaglini, D. Perkis, and R. M. Johnson, "Storage of poisonous substances and firearms in 
homes with young children visitors and older adults," American Journal of Preventive Medicine, vol. 28, no. 1, pp. 109-115, 2005.

[18] T. L. Albright and S. K. Burge, "Improving firearm storage habits: impact of brief office counseling by family physicians," Journal of the American Board of Family Practice, vol. 16, no. 1, pp. 40-46, 2003.

[19] M. H. Rathore, "Physician 'gag laws' and gun safety," Virtual Mentor, vol. 16, no. 4, pp. 284-288, 2014.

[20] Center for Disease Control, "Web-based Injury Statistics Query and Reporting System (WISQARS)," October 2014, http://www .cdc.gov/injury/wisqars/index.html.

[21] G. J. Wintemute, C. A. Parham, J. J. Beaumont, M. Wright, and C. Drake, "Mortality among recent purchasers of handguns," The New England Journal of Medicine, vol. 341, no. 21, pp. 15831589, 1999.

[22] J. J. Mann, A. Apter, J. Bertolote et al., "Suicide prevention strategies: a systematic review," The Journal of the American Medical Association, vol. 294, no. 16, pp. 2064-2074, 2005.

[23] National Strategy for Suicide Prevention: Goals and Objectives for Action, 2012, http://www.surgeongeneral.gov/library/ reports/national-strategy-suicide-prevention/full-report.pdf. 


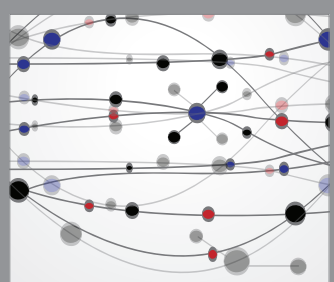

The Scientific World Journal
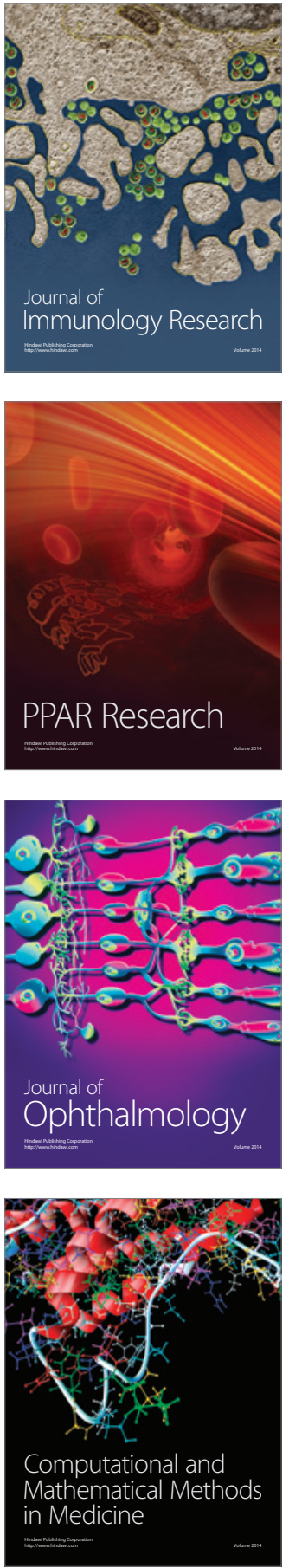

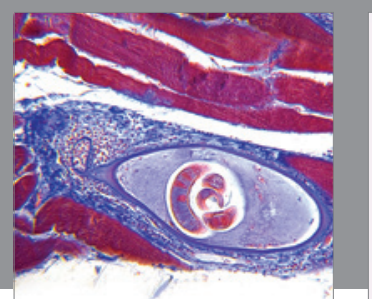

Gastroenterology Research and Practice

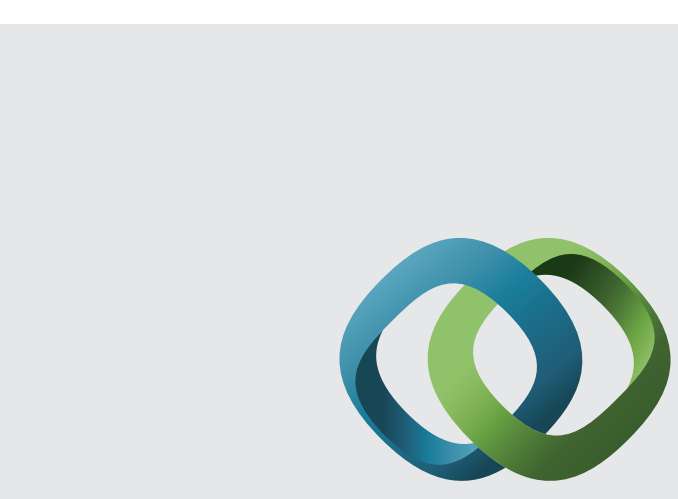

\section{Hindawi}

Submit your manuscripts at

http://www.hindawi.com
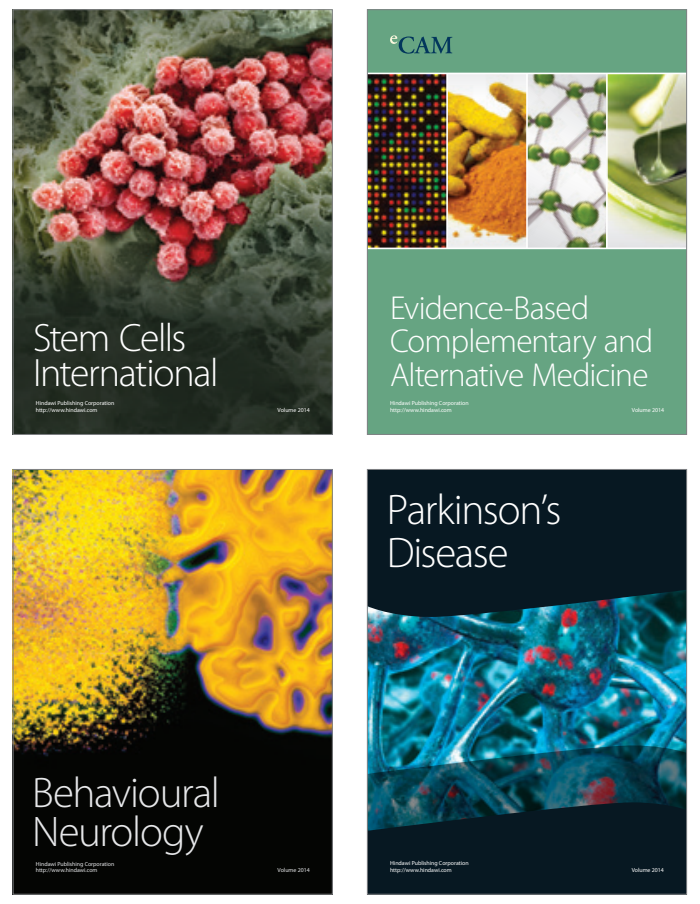
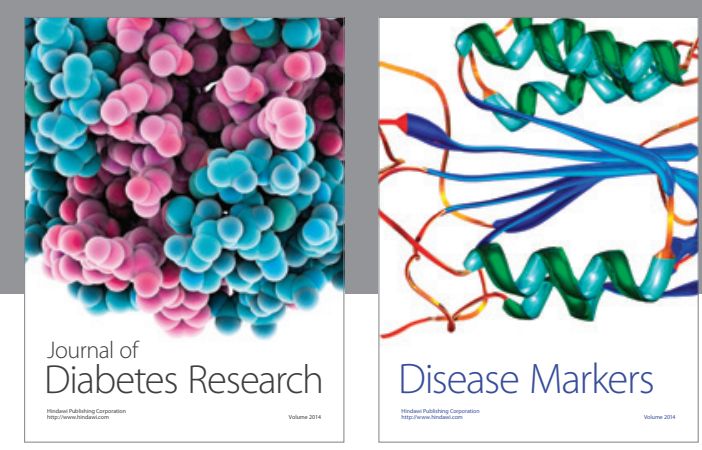

Disease Markers
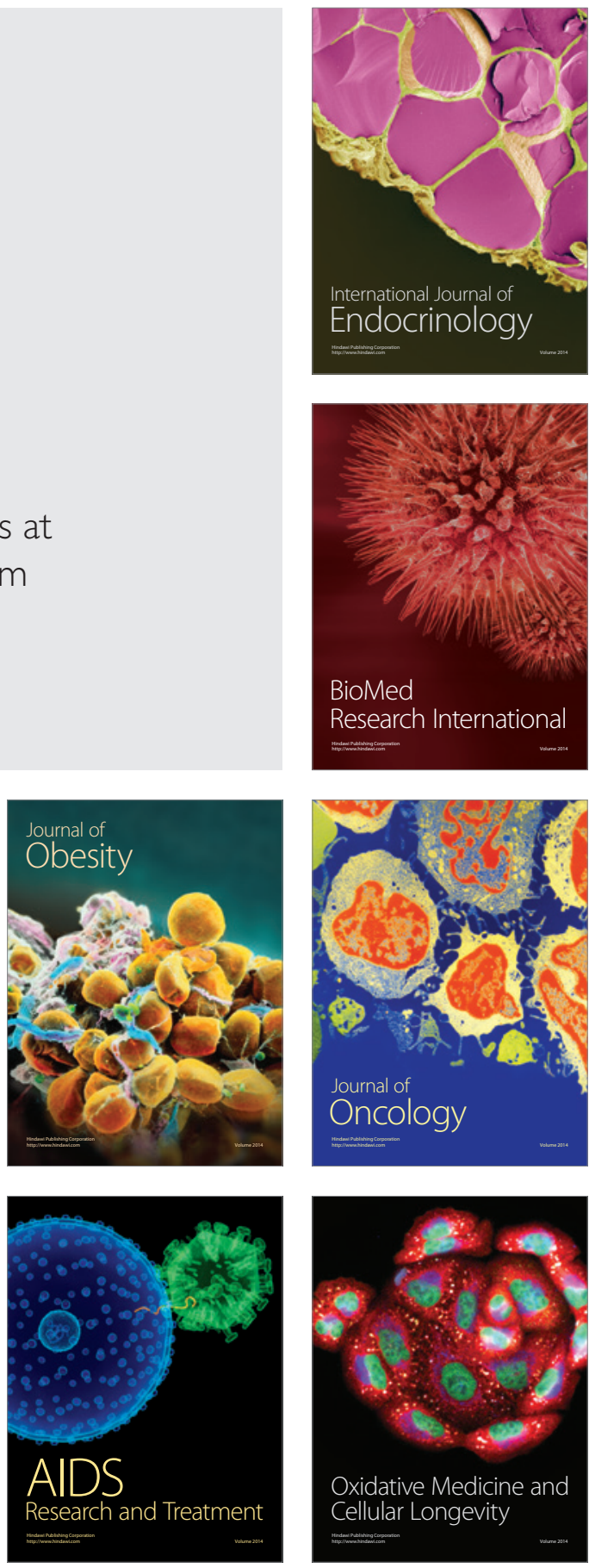